\title{
Role of miRNAs in CD4 T cell plasticity during inflammation and tolerance
}

\author{
Apoorva Sethi ${ }^{\dagger}$, Neeraja Kulkarni $^{+}$, Sandip Sonar ${ }^{\dagger}$ and Girdhari Lal*
}

National Centre for Cell Science, Pune, MH, India

Edited by:

Peng Jin, Emory University School of Medicine, USA

Reviewed by:

Peng Jin, Emory University School of Medicine, USA

Bing Yao, Emory University, USA

${ }^{*}$ Correspondence:

Girdhari Lal, National Centre for Cell Science, NCCS complex,

Ganeshkhind, Pune,

MH 411007, India.

e-mail: glal@nccs.res.in

tThese authors equally contributed to this work.
Gene expression is tightly regulated in a tuneable, cell-specific and time-dependent manner. Recent advancement in epigenetics and non-coding RNA (ncRNA) revolutionized the concept of gene regulation. In order to regulate the transcription, ncRNA can promptly response to the extracellular signals as compared to transcription factors present in the cells. microRNAs (miRNAs) are ncRNA ( $\sim 22 \mathrm{bp}$ ) encoded in the genome, and present as intergenic or oriented antisense to neighboring genes. The strategic location of miRNA in coding genes helps in the coupled regulation of its expression with host genes. miRNA together with complex machinery called RNA-induced silencing complex (RISC) interacts with target mRNA and degrade the mRNA or inhibits the translation. CD4 $T$ cells play an important role in the generation and maintenance of inflammation and tolerance. Cytokines and chemokines present in the inflamed microenvironment controls the differentiation and function of various subsets of CD4 T cells [Th1, Th2, Th17, and regulatory CD4 $T$ cells (Tregs)]. Recent studies suggest that miRNAs play an important role in the development and function of all subsets of CD4 T cells. In current review, we focused on how various miRNAs are regulated by cell's extrinsic and intrinsic signaling, and how miRNAs affect the transdifferentiation of subsets of CD4 T cell and controls their plasticity during inflammation and tolerance.

Keywords: miRNA, $T$ cell plasticity, tolerance, regulatory CD4 T cells, Th17 cells

\section{INTRODUCTION}

It has been speculated that about $1.5-3 \%$ of human genome encodes for the protein and remaining large fraction exist as non-protein coding sequences. Extra emphasis has been given on the effect of protein-protein and protein-DNA interaction on regulation of gene expression. Advancement in epigenetics and non-coding RNA (ncRNA) already proved that gene expression in a specific-cell can be fine-tuned based on the signals present in the tissue microenvironment (Esteller, 2011; Kaikkonen et al., 2011). New generation sequencing techniques such as RNA-seq, whole transcriptome analysis, and tiling arrays indicated that $\sim 90 \%$ of genomic DNA is transcribed (Mortazavi et al., 2008; Pan et al., 2008; Wilhelm et al., 2008; Lindberg and Lundeberg, 2010). ncRNA like ribosomal RNA, tRNA, small nucleolar RNA (snoRNA), and small nuclear RNA (snRNA) are also transcribed from the genome but never translate into protein. These ncRNA controls the transcription and translation of the several genes (Costa, 2010). ncRNAs are comprises of a class of heterogeneous member that ranges in size from few to several hundred nucleotides. Based on their size and origin, they are identified as microRNAs (miRNAs), PIWI-interacting RNAs (piRNAs), long non-coding RNAs (lncRNAs), recently identified

Abbreviations: AGO, Argonaute; APCs, Antigen presenting cells; EAE, Experimental autoimmune encephalomyelitis; miRNA, microRNA; MS, Multiple sclerosis; ncRNA, Non-coding RNA; RISC, RNA-induced silencing complex; RITS, RNA-induced transcriptional silencing; shRNA, Short hairpin RNA; Tregs, Regulatory CD4 T cells. enhancer RNAs (eRNAs), promoter-associated RNAs (PARs), transcription start site-associated RNAs (TSSa-RNAs), and transcription initiation RNAs (tiRNAs) (Taft et al., 2009; Esteller, 2011). ncRNAs perform several important functions that control the development, survival, cell migration, cell differentiation, apoptosis, immune response, maintaining genome stability, and stress responses by regulating the gene expression (Kaikkonen et al., 2011; Tomankova et al., 2011). Among the various ncRNAs, miRNAs are extensively studied in the context of their role in dynamic regulation and micromangement of transcriptome in the various cells.

Several subsets of CD4 T cells have been identified, and they all are developed in thymus from a common precursor $\mathrm{T}$ cells. Based on the cytokine secretion and function, these cells are classified as Th1, Th2, Th9, Th17 and regulatory CD4 T cell (Treg). Recent studies showed that these cells are not terminally differentiated but have potential to differentiate into other CD4 $\mathrm{T}$ subset (Lal and Bromberg, 2009; O'Shea and Paul, 2010; Lal et al., 2011; Gao et al., 2012). The differentiation of different subsets of CD4 T cells are regulated by cytokine and other extracellular signals present in the tissue microenvironment (Lal and Bromberg, 2009; O'Shea and Paul, 2010; Lal et al., 2011; Gao et al., 2012). Under the influence of different extracellular inflammatory stimuli, Tregs which have potential to suppress inflammation and help in the maintenance of tolerance can transdifferentiate into the pathogenic Th1 and Th17 cells (Xu et al., 2007; Lal et al., 2011; Kanno et al., 2012). It has been reported that under inflammatory condition 
$\mathrm{CD}^{+}{ }^{+}$Foxp $3^{+}$Treg (nTreg) down-regulates Foxp3 expression (a master transcription factor for nTreg) and differentiated into the CD4 follicular helper T cells (Tfh) (Tsuji et al., 2009). It has also been reported that loss of Foxp3 in nTreg-induced IL-4 expression and converted into Th2 lineage leading to development of autoimmune colitis (Wang et al., 2010). It has been shown that helminth antigens induced the differentiation of Th2 cells into Tfh cells (Zaretsky et al., 2009). Tfh cell can also differentiate into other effector subsets such as Th1, Th2, and Th17 cells ( Lu et al., 2011). Bending et al. reported that under lymphopenic condition, Th17 cells differentiated into Th1 cells (Bending et al., 2009). Similarly, in presence of IFN- $\gamma$ Th2 cells re-programmed into GATA $^{+}{ }^{+}$T-bet $^{+}$cell subset and showed combined function of Th2 and Th1 cells (Hegazy et al., 2010). All these studies clearly demonstrated that CD4 T cells possess fair amount of plasticity to differentiate into various subsets of CD4 T cell lineage, and inflammation in the tissue microenvironment play an important role in this cellular re-programming. The detail cellular and molecular mechanisms that regulate plasticity of CD4 T cell differentiation and function are not completely understood.

Recent studies have suggested strong association of miRNAs in many inflammatory and autoimmune diseases (Chong et al., 2008; Tomankova et al., 2011; Contreras and Rao, 2012). In this review, we have discussed recent advances in the understanding of miRNA biogenesis and its role in the development, differentiation, and function of different subset of $\mathrm{CD} 4^{+} \mathrm{T}$ cells, and how miRNAs regulate the plasticity of CD4 $\mathrm{T}$ cells during inflammation and tolerance.

\section{MIRNA BIOGENESIS}

Majority of miRNAs from introns of protein coding host genes are transcribed by RNA polymerase II (RNA pol II). Some of miRNAs are also formed by splicing of RNA polymerase III products. Biogenesis of miRNA is a highly regulated multi-step process, initially carried out into the nucleus but later processed matured in the cytoplasm (Figure 1). In the nucleus,

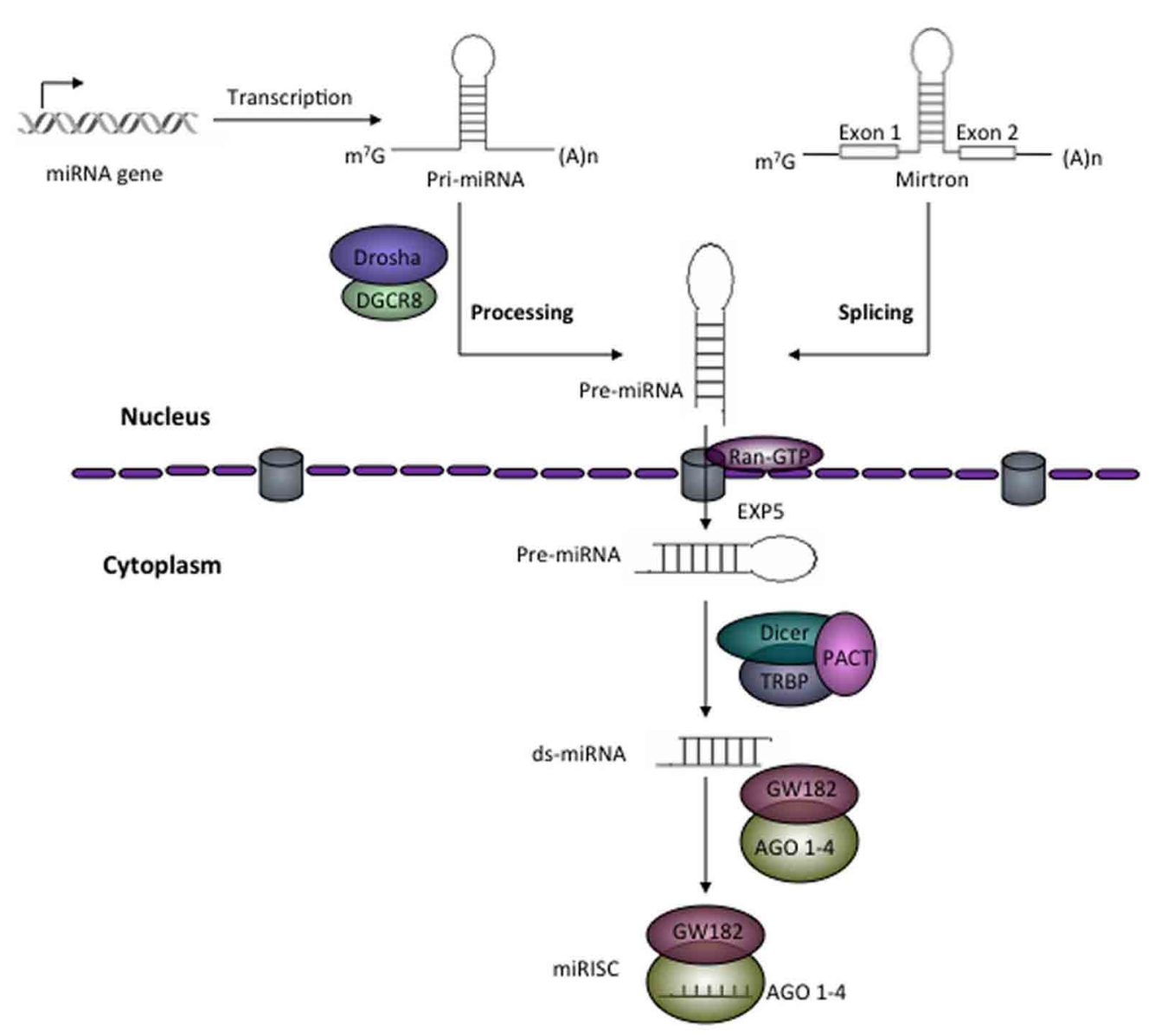

FIGURE 1 | Schematic representation of miRNA biogenesis. RNA polymerase II transcribes the miRNA gene and produces hairpin structured pri-miRNA that contains $5^{\prime}$ cap and $3^{\prime}$ poly-A tail. In the nucleus, Drosha in association with DGCR8, a ds-RNA-binding protein generates about 55-70 nt long precursor miRNA (pre-miRNA). In eukaryotes, some pre-miRNAs are generated from mirtrons as a product of splicing reaction. With the help of Ran-GTP bound exportin-5 pre-miRNAs are exported from the nucleus to cytoplasm. In the cytoplasm, Dicer together with TAR RNA-binding protein (TRBP) or PACT removes the loop and generates miRNA duplex from pre-miRNAs. The miRNA duplex (ds-miRNA) is then loaded into Argonaute (AGO) proteins (in the case of humans AGO 1-4). One of the strands of ds-mRNA called guide strand retained in the AGO and with other effector protein factors forms miRNA-induced silencing complex (miRISC). 
primary miRNA transcripts (pri-miRNA) a double-strandedRNA containing stem-loop are produced as a result of RNA pol II driven transcription. Pri-miRNAs are further processed by Drosha (RNase III family member) and a cofactor DGCR8, a double-stranded-RNA-binding protein which recognize about $10 \mathrm{bp}$ near hairpin structure and cleaves both strands of stem at sites near the base of primary stem-loop, and resulting hairpin precursor miRNA (pre-miRNA) (Lee et al., 2003). Droshaindependent processing of the miRNAs is also reported, especially for those miRNA derived from intronic region as a product of splicing reaction (Berezikov et al., 2007; Ruby et al., 2007). Later, pre-miRNAs transported to the cytoplasm by exportin5 (Figure 1). Exportin-5 needs another cofactor Ran bound to GTP for export function, and this Ran-GTP bound exportin-5 recognizes $3^{\prime}$ overhangs of pre-miRNA (Bohnsack et al., 2004; Lund et al., 2004). In the cytoplasm, loop region of pre-miRNA is removed by another RNase-III family member known as "Dicer." Dicer is associated with TAR RNA-binding protein (TRBP) or PACT and produce about $22 \mathrm{nt}$ long miRNA duplex from premiRNA (Hutvagner et al., 2001; Chendrimada et al., 2005; Lee et al., 2006). Together, Dicer, TRBP, or PACT along with Argonaute 1-4 (AGO 1-4) form a complex known as RISCloading complex (RLC). RLC loads the guide strand (one of the two strands which has unstable base pairing at its $5^{\prime}$ end) into the RNA-inducing silencing complex (RISC) and process the duplex-miRNA (Chendrimada et al., 2005). In human, AGO proteins bind to the guide miRNA strand, interacts with glycinetryptophan protein (GW182) and finally form the major component of miRISC (Jakymiw et al., 2005; Liu et al., 2005). miRISC regulates the gene expression either by suppressing translation or by mediating the deadenylation and further degradation of target mRNA (Figure 1).

\section{REGULATION OF MIRNA BIOGENESIS}

It has been reported that miRNA biogenesis is a very tightly regulated process, and a number of regulatory mechanisms with negative feedback control participate in the generation of pri-miRNA (Johnston et al., 2005; Kim et al., 2007; Turner and Slack, 2009). Post-transcription processing of pri-miRNA provides another layer of regulatory mechanism for miRNA biogenesis such as Drosha inhibitory molecules like lin-28 inhibits processing of let7 primary transcript (Newman et al., 2008). It has been reported that mutation in TARBP2 protein, an integral component of Dicer1-containing complex, leads to destabilization of processing machinery. It is also found that TARBP2 protein controls post-transcriptional processing of miRNA and promotes tumor growth (Melo et al., 2009). It has been reported that DGCR8 required for the Drosha-mediated miRNA processing and negatively regulates generation of pre-miRNA (Triboulet et al., 2009). Nuclear export of pre-miRNA by Ran-GTP bound exportin- 5 can also functionally regulate the generation of functional miRNA (Lee et al., 2008). RNA editing has been reported to regulate the miRNA generation by changing the sequence of pri-miRNA or pre-miRNA leading to decreased (Kawahara et al., 2007a) or increased (Kawahara et al., 2008) efficiency of miRNA generation, and also alteration of miRNAs target specificity (Kawahara et al., 2007b).

\section{MECHANISMS OF MIRNA FUNCTION}

It is well-established that miRNAs regulate gene expression posttranscriptionally, mostly by either repressing the translation or affecting the stability of target mRNA in the cytoplasm (Figure 2). Most of the miRNAs function in the cytoplasm but some miRNAs are also reported to be localized in the nucleus (such as miR-29b) (Hwang et al., 2007) and some are secreted outside of the cells (Valadi et al., 2007). miRNAs were also reported to positively regulate the gene expression (Vasudevan and Steitz, 2007; Vasudevan et al., 2007; Orom et al., 2008). This suggests that various miRNAs can function differently in different cell-types and can control the development and differentiation of cells.

miRNAs REGULATE GENE EXPRESSION BY DEGRADING TARGET mRNA

There is a reciprocal correlation between expression of miRNAs and their target mRNAs (Huntzinger and Izaurralde, 2011). This suggests that miRNAs function by targeting mRNA degradation. miRNA binds to the target mRNA with partial base pair complementarity. Studies in animal cells and in vitro cell-free extract have revealed that binding of miRISC to its target mRNA recruits deadenylase complex consist of CAF1/CCR4/NOT which removes $3^{\prime}$ poly-A tail from target mRNA (Behm-Ansmant et al., 2006; Wu et al., 2006). The deadenylation process followed by decapping mediated by DCP1 and DCP2 together with other protein factors. Decapped mRNAs are targeted by XRN1 a $5^{\prime}-3^{\prime}$ exonuclease present in the cytoplasm leading to degradation of mRNA (Parker and Song, 2004; Behm-Ansmant et al., 2006). Therefore, removal of both the ends of mature mRNA by miRNA-mediated mechanism affects the stability of mRNA in the cytoplasm and renders them to undergo degradation (Figure 2).

\section{miRNAs REGULATE GENE EXPRESSION BY REPRESSING TRANSLATION OF TARGET mRNA}

Several studies using wide variety of cells as well as in cell-free system suggested that miRNAs repress the translation of target mRNA at both initiation and post-initiation stages. There are several evidences that support the inhibition of translation at initiation stage such as target mRNAs having functional $\mathrm{m}^{7} \mathrm{Gppp}$-cap at their $5^{\prime}$ end were repressed whereas a synthetic non-functional $5^{\prime}$ Appp-cap and internal ribosome entry site (IRES)-mediated translation was unaffected (Humphreys et al., 2005; Mathonnet et al., 2007). Using bi-cistronic construct, Pillai et al. showed that only first cistron which had $5^{\prime}$ cap was affected but cistron having IRES did not show any change in translation (Pillai et al., 2005). Similarly, it has been reported that AGO proteins compete with eIF4E for binding at $5^{\prime}$ cap of target mRNA and inhibit the translation (Kiriakidou et al., 2007). These evidences clearly suggest that miRNA-mediated repression at translation initiation stage is cap-dependent. In contrast, it has also been reported that miRNAs repress mRNAs that are translated by IRES-dependent mechanism (Petersen et al., 2006; Lytle et al., 2007). Other mechanisms regulated by miRNA (acting at post-initiation of translation) include inhibition of elongation steps, degradation of protein during ongoing translation, and premature termination of translation are reviewed nicely elsewhere (Huntzinger and Izaurralde, 2011). 


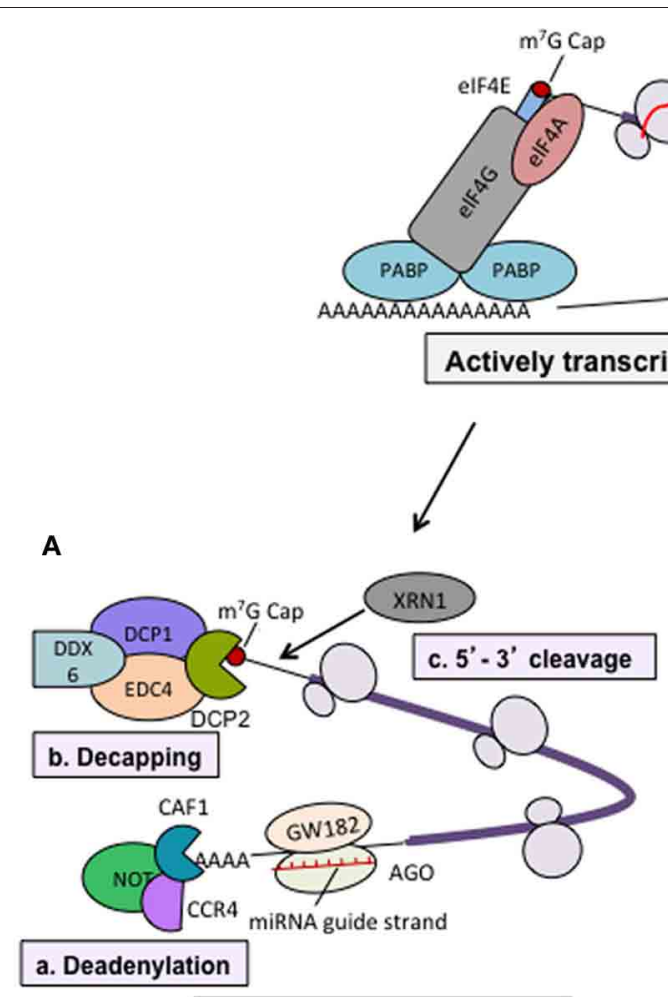

Target mRNA degradation

FIGURE 2 | Mechanisms of miRNA-mediated gene regulation. miRNA-mediated gene regulation mostly occurred by two ways; affecting mRNA stability in the cells or suppressing translation of target mRNA. miRNA-induced silencing complex (miRISC) consisting of miRNA guide strand, AGO 1-4 (in humans) and among others trinucleotide-repeat-containing protein GW182, altogether perform regulating function. Actively transcribing mRNA forms a circular structure via the interaction of elF4F (elF4A, elF4E, elf4G) with $5^{\prime}$ cap and poly-A-binding protein (PABP) that increases the efficiency of translation. (A) Regulation of mRNA stability. Binding of miRISC to $3^{\prime}$-UTR of target mRNA recruit the deadenylase complex consisting of
CAF1-CCR4-NOT that removes the $3^{\prime}$ poly-A tail. It has also been reported that deadenylation may also leads to removal of cap by DCP (DCP1 and DCP2)-mediated decapping (Behm-Ansmant et al., 2006). DCP1 and DCP2 along with some other factors such as EDC4, DDX6 removes $5^{\prime} \mathrm{m}^{7} \mathrm{G}$ cap and decapped mRNA provides a platform for $5^{\prime}-3^{\prime}$ exonuclease (XRN1 is one of characterized members) leading mRNA degradation (Parker and Song, 2004). (B) Regulation of target mRNA translation. miRNAs can also regulate translation by suppressing translation initiation (reports suggest that GW182 compete with elF4E for $5^{\prime}$ cap binding during initiation stage), elongation, co-translational protein degradation, and premature termination.

\section{ROLE OF miRNAs IN THE IMMUNE SYSTEM}

miRNAs are known to control many important processes such as development, survival, proliferation, differentiation, and function of immune cells. Several miRNAs have been reported to control the expression of cytokines, chemokines, growth factors, cell adhesion molecules, co-stimulatory molecules, and transcription factors (Table 1). For example, over-expression of miR-181 in hematopoietic precursor cells can direct the lymphoid differentiation into $\mathrm{B}$ cell lineage and inhibit development of $\mathrm{T}$ cell (Chen et al., 2004). Deletion of Dicer is embryonic lethal. However, conditional deficiency of Dicer only in early developmental stage of $\mathrm{T}$ cells $\left(\mathrm{CD} 4^{-} \mathrm{CD} 8^{-}\right.$double-negative thymocytes; using lck-Cre model) (Lee et al., 2001) or later T cell developmental stage $\left(\mathrm{CD}^{+}\right.$single-positive thymocytes; using $\mathrm{CD} 4$-Cre model) reported to have no change in the mature $\mathrm{CD} 4$ or CD8 lineage choices (Cobb et al., 2005; Muljo et al., 2005). However, deletion of Dicer in T cells showed generation of reduced numbers of total TCR $\alpha / \beta$ thymocytes in thymus (Cobb et al., 2005; Muljo et al., 2005). This suggests that miRNA plays an important role in the development of $\mathrm{T}$ cells in thymus. It has been reported that deficiency of Dicer in CD4 T cells (CD4-cre model) did not blocked IFN- $\gamma$ production (Th1 lineage cytokine) even under Th2 polarization condition. It suggests that miRNA expression was required in each specific stage in order to control the function of the specific lineage of CD4 T cells (Muljo et al., 2005). miRNAs were also reported to mediate antibody class switching, formation of germinal center and activation of antigen presenting cells (APCs), and secretion of pro-inflammatory cytokines (Baltimore et al., 2008). CD4 ${ }^{+} \mathrm{T}$ cells occupy central position in the adaptive immune system, and they provide help to B cells and $\mathrm{CD} 8^{+} \mathrm{T}$ cells for their differentiation and effector function. Importance of various miRNAs in the differentiation and function of different subset of CD4 T cells are depicted in Figure 3. Role of miRNAs in the immune responses are well-reviewed elsewhere (O'Connell et al., 2012). In present review, we are focusing on role of miRNAs in the plasticity and its function in different subset of $\mathrm{CD}^{+} \mathrm{T}$ cells during inflammation and tolerance. 


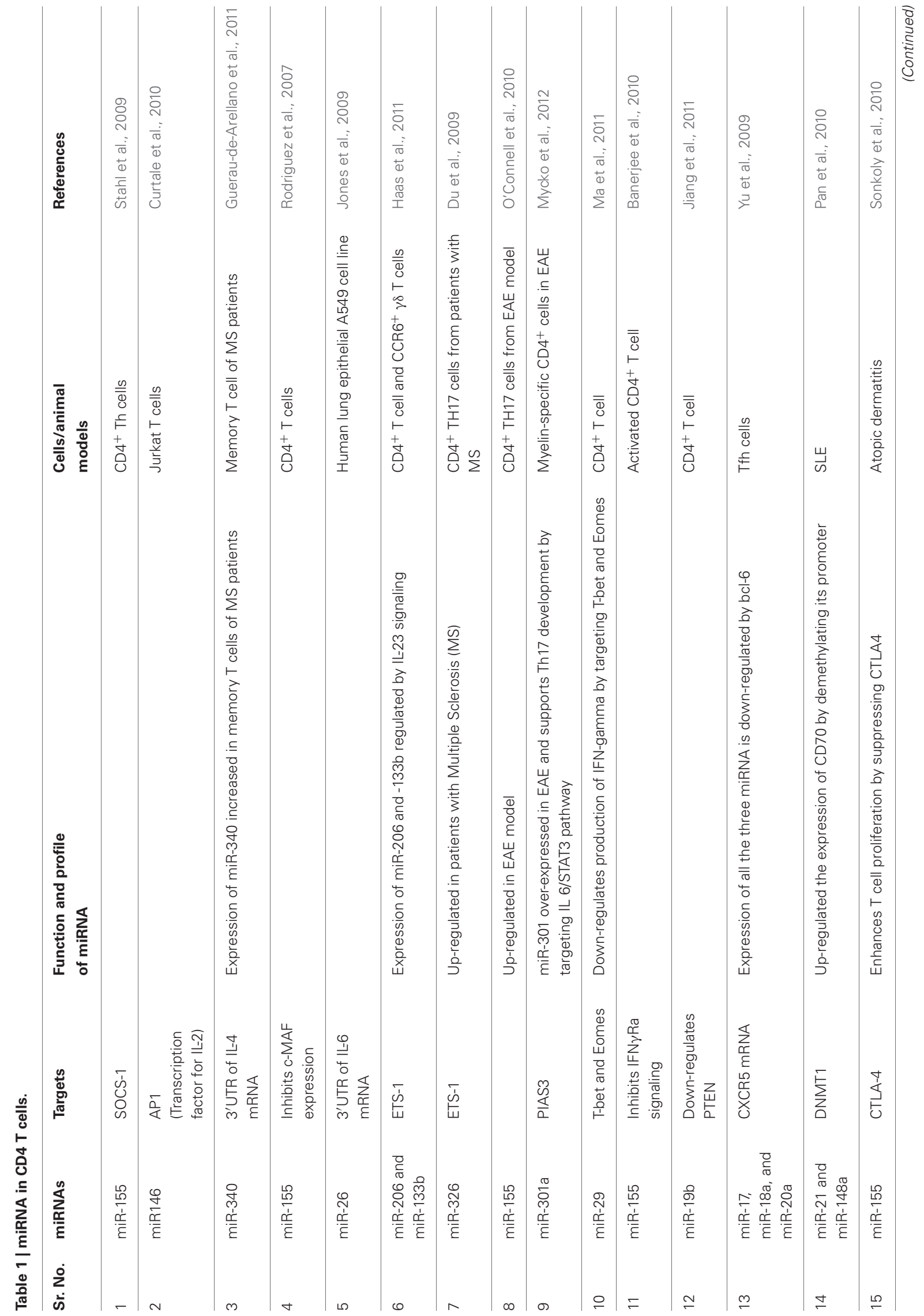




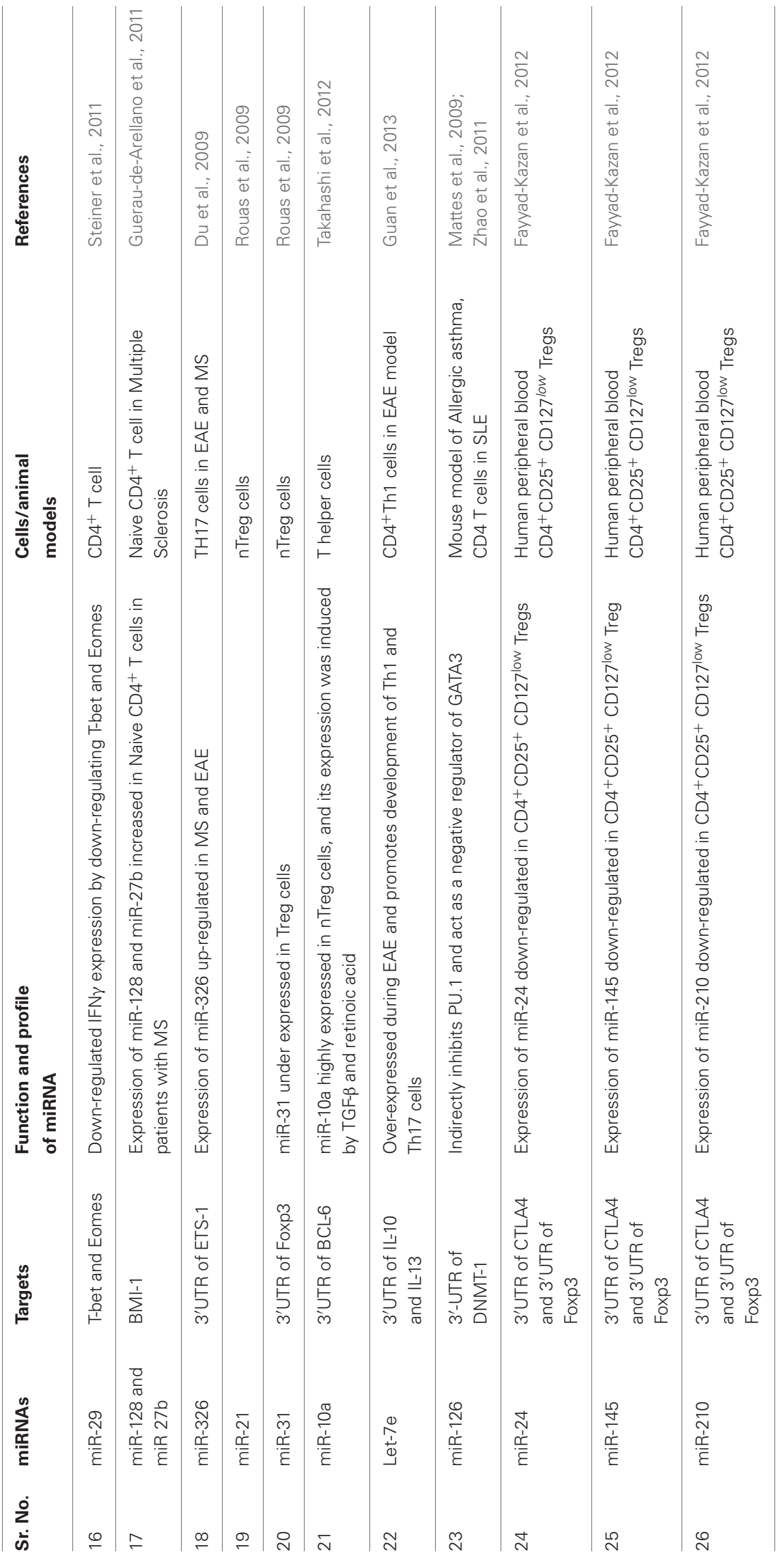




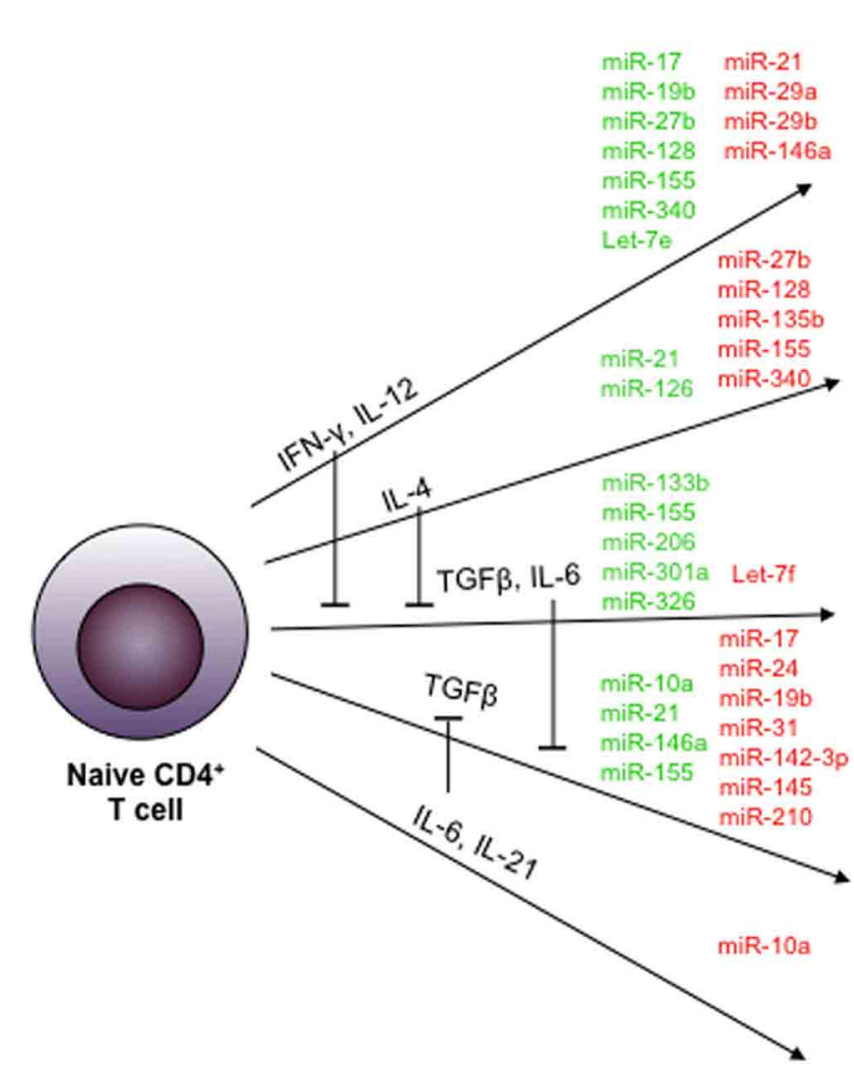

FIGURE 3 | miRNAs control the differentiation of $\mathrm{CD}^{+}{ }^{+} \mathrm{T}$ helper cell subsets. miRNAs regulates the differentiation of different effector (Th1, Th2, Th17, and Tfh) and regulatory (Treg) sub-population of $\mathrm{CD}^{+}$

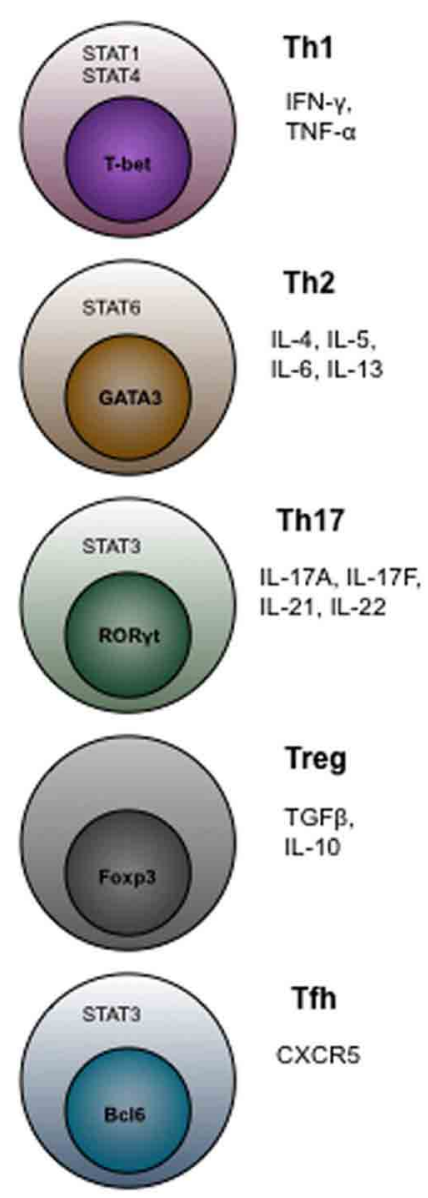

\section{Defense against intracellular parasites}

Allergy, Asthma, Controls parasites and extracellular pathogens

Immune homeostasis,

Maintains tolerance

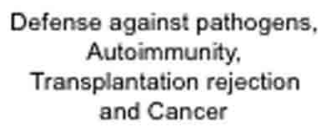

Defense against pathogens. Autoimmunity, Transplantation rejection and Cancer

\section{Help germinal centre B cells to make antibodies, Affinity maturation and antibody class switching}

T helper cells. miRNAs shown in green color are reported to positively regulate whereas those in red color negatively regulate their differentiation.

\section{ROLE OF MIRNA IN REGULATION OF Th1/Th2 BALANCE}

Helper $\mathrm{CD}^{+} \mathrm{T}$ cells function both in contact-independent (by secreting cytokines and chemokines) and contact-dependent manner (by interacting with co-stimulatory molecules). IFN- $\gamma$ secreted by Th1 cells activates the APCs (macrophages, dendritic cells, and $\mathrm{B}$ cells), and induces increased surface expression of class-II MHC and co-stimulatory molecules on APCs, and boosts the antigen presenting function of APCs. APCs secrete IL-12 which promotes phosphorylation of STAT4 that in turn induces expression of transcription factor T-bet in CD4 T cells and control the production of IFN $\gamma$. IL-12-induced IFN- $\gamma$ initiates a positive feedback loop which further promotes production of IL-12. Positive feedback-induced production of IL-12 gives a strong Th1 response.

Several miRNAs are known to regulate the secretion of IFN$\gamma$ and IL-12 cytokines which required for the differentiation of Th1 cells. NK cells play important role in the innate immunity. It has been shown that miR-132, miR-200, miR-212a regulate IL12 production in NK cells (Huang et al., 2011). These miRNAs negatively regulate STAT4 and inhibit expression of IL-12 and
IFN- $\gamma$ (Huang et al., 2011). In the helper CD4 T cells, miR-29a and miR-29b inhibit production of IFN- $\gamma$ by targeting T-bet and Eomes, lineage-specific transcription factors that regulate the differentiation of Th1 cells (Ma et al., 2011; Steiner et al., 2011). Th1/Th2 cells are known to be involved in the various autoimmune and inflammatory diseases. Increased expression of miR27b, miR-128, and miR-340 in $\mathrm{CD}^{+} \mathrm{T}$ cells has been reported in multiple sclerosis (Guerau-de-Arellano et al., 2011). These miRNAs promote effector function of Th1 by inhibiting the proliferation of Th 2 cells. miR-128 represses the expression of Bim1, a proapoptotic molecule required for stabilization of GATA3 (transcription factor for Th2 cell lineage), whereas miR-340 downregulates the expression of IL-4 and together these miRNAs direct the differentiation of Th1 cells (Guerau-de-Arellano et al., 2011). Increased expression of miR-155 is reported in experimental autoimmune encephalomyelitis (EAE) and promotes differentiation of inflammatory Th17 cells (O'Connell et al., 2010). miR-155 also suppresses c-Maf a transactivator of IL-4 and inhibits proliferation of Th2 cell (Rodriguez et al., 2007). Deficiency of miR-155 leads to excessive Th2 response and decreased IL-17 and IL-22 
production in collagen-induced arthritis (Bluml et al., 2011). Over-expression of miR-155 in activated T cells leads to the differentiation of Th1 response (Banerjee et al., 2010). miR-155 target site is also found on $3^{\prime}$-untranslated region of IFN- $\gamma \mathrm{R} \alpha$, and inhibition of miR-155 leads to induction of IFN- $\gamma \mathrm{R} \alpha$ (Banerjee et al., 2010). It has been reported that miR-146 expression into naïve CD4 T cells was low but showed increased expression into effector Th1 (Monticelli et al., 2005) and Treg (Cobb et al., 2006), but not in Th2 cells (Monticelli et al., 2005). miR-150 expressed in naïve CD4 $\mathrm{T}$ cells but down-regulated after activation and differentiation into Th1, Th2, and Treg (Monticelli et al., 2005; Cobb et al., 2006; Curtale et al., 2010). These results suggest that various miRNAs involve in the regulation of Th1 and Th2 cell differentiation and function.

It has been reported that miR-17-92 cluster was involved in the generation of Th1 cells. Deficiency of miR-17-92 leads to the reduced expression of T-bet and IFN- $\gamma$ and promotes differentiation of the Foxp $3^{+}$Treg (Jiang et al., 2011). Analysis of functional targets showed that miR-17 targets TGF $\beta$ RII and cAMP-responsive element-binding protein 1 (CREB1) and both of these molecules are known to involved in Treg differentiation. Therefore, this cluster displays a unique mechanism that reciprocally regulates Th1 and Treg generation. Wu et al. showed that miR-21 expression was inversely correlated with IL-12 production in murine APCs which further leads to reduction in IL-12-dependent differentiation of Th1 cells (Wu et al., 2012).

miR-29b targets T-bet and IFN- $\gamma$ which are signatures of Th1 cells (Smith et al., 2012). Furthermore, IFN- $\gamma$ in CD4 T cells were found to enhance miR-29b expression via STAT1 binding to the promoter of miR-29ab1, and forms a negative feedback loop (Smith et al., 2012). Recently, it has been reported that expression of miRNA Let-7e was up-regulated in an encephalitogenic CD4 T cells in EAE mice. Silencing of Let-7e expression in vivo using antagonist anti-miR increased $\mathrm{Th} 2$ response and inhibited Th1 and Th17 responses leading to attenuation of EAE (Guan et al., 2013). This suggests that Let-7e has important role in balancing pro-inflammatory and anti-inflammatory responses by reciprocally tuning the function of subset of CD4 T cells. Foster's group has showed that miR-126 level was correlated with the generation of inflammatory Th2 cells in the mouse model of allergic asthma. Suppression of miR-126 expression in the airway resulted into down-regulation of IL-4, IL-5, and IL-13 production by Th2 cells and up-regulation of Oct binding factor 1 (OBF.1), which is a negative regulator of transcription factor PU.1 (Brunner et al., 2007). PU.1 inhibits the expression of Th2specific transcription factor GATA3. Thus, this study provided a mechanism by which miR-126 promotes the generation of Th2 cells.

All these evidences indicate that several miRNAs regulates the differentiation and function of Th1 and Th2 and controls the pathology.

\section{ROLE OF miRNA IN Treg CELLS}

Regulatory $\mathrm{CD} 4{ }^{+} \mathrm{CD} 25^{+} \mathrm{T}$ cells (Tregs) play an important role in maintaining the homeostasis and immunological tolerance by suppressing pathogenic $\mathrm{CD}^{+}{ }^{+} \mathrm{T}$ cell response (Lal and Bromberg,
2009; Lal et al., 2009). It has been reported that deletion of Dicer in the late stage of $\mathrm{T}$ cell development did not interfere the process of development and differentiation of $\mathrm{T}$ cells (Cobb et al., 2005; Muljo et al., 2005). However, lck-Cre-mediated conditional deletion of Dicer into CD4 T cells reduces the number of Foxp $3^{+}$ nTreg in thymus and secondary lymphoid organ (Cobb et al., 2006). The lack of Dicer in the $\mathrm{CD}^{+}{ }^{+}$single positive stage blocks the TGF $\beta$-induced differentiation of Foxp $3^{+}$Treg in vitro (Cobb et al., 2006). Deletion of Dicer in Foxp ${ }^{+}$Treg (Foxp3-GFP-hCre model) leads to loss of suppression function and induces their differentiation into T helper memory phenotype (Zhou et al., 2008). Dicer deficiency in Foxp $3^{+}$cells leads to the development of fatal autoimmune diseases resembling the Foxp3 knockout phenotype (Zhou et al., 2008). These observations clearly suggest that miRNAs at different stages of $\mathrm{T}$ cell differentiation regulate different functions. Dicer is not only involved in the processing of miRNA but also involved in the processing of short hairpin RNA (shRNA). Therefore, phenotype reported in Dicer-deficient animals accounts for the loss of not only miRNA but also shRNA. RNase III enzyme Drosha is specifically required for generating miRNA and deletion of Drosha in the CD4 T cells leads to spontaneous $\mathrm{T}$ cell activation, inflammatory diseases, and premature lethality (Chong et al., 2008). Ablation of Drosha specifically in the Foxp $3^{+} \mathrm{T}$ cells leads to early onset of lymphoproliferative disease as observed in $\mathrm{T}$ cell or Foxp3-deficient mice (Chong et al., 2008). These reports suggest that different miRNA processing enzymes in CD4 T cells can affect the differentiation and function of nTreg.

miR-155 is highly expressed in the Treg (Zheng et al., 2007). It has been shown that Foxp3 binds to the promoter region of bic gene, which is transcribed into miR-155 precursor mRNA (Marson et al., 2007). Deficiency of miR-155 showed reduced Treg in the thymus and periphery, however Treg from miR-155 deficient animal do not show any defect in suppressive function both in vitro and in vivo (Kohlhaas et al., 2009). Furthermore, Rudensky's laboratory showed that deficiency of miR-155 leads to the increased expression of suppressor of cytokine signaling 1 (SOCS1) leading to impaired activation of signal transducer and activator of transcription factor 5 (STAT5) (Lu et al., 2009). STAT5 signaling is required for the survival and function of Tregs. Rudensky's group also reported that miR146a is also prevalently expressed in Treg cells and critical for Treg function. In addition, they also showed that deficiency of miR146a increases the number of Tregs but impaired their function. miR146a directly targets STAT1 which is a key transcription factor required for IFN- $\gamma$ signaling and Th1 differentiation thus helps in Treg function ( $\mathrm{Lu}$ et al., 2010). miR146a knocked out mice showed increased Th1 phenotype which is similar to specific depletion of SOCS1 (a negative regulator of STAT1) in Foxp $3^{+}$Treg leading to breakdown of tolerance and massive autoimmune inflammation ( $\mathrm{Lu}$ et al., 2010).

CD4 T cell activation requires low levels of intracellular cAMP. It has been reported that CAMP play an important role in contactdependent manner to control the suppressive function of nTreg. nTreg contains high level of cAMP compared to the naïve or effector CD4 T cells (Bopp et al., 2007). nTreg releases intracellular cAMP into effector $\mathrm{T}$ cells through tight junction and 
suppresses the effector cell function (Bopp et al., 2007). It has been shown that activated helper CD4 T cell contains high levels of phosphodiesterase, an enzyme responsible for turnover of cAMP. This enzyme is down regulated in the nTreg (Marson et al., 2007; Zheng et al., 2007). It has been reported that blocking of cAMP degradation by phosphodiesterase 4 inhibitor lead to increased Tregs suppressive function (Bopp et al., 2009). Elevated levels of intracellular cAMP blocks IL-12 signaling pathway in target cells and thus suppress its differentiation into Th1 lineage. In the same context, Huang et al. showed that downregulation of miR142-3p is essential for Treg function (Huang et al., 2009). miR-142-3p maintains low levels of intracellular cAMP by targeting adenylyl cyclase (AC) 9 mRNA (Huang et al., 2009). In Treg cells, Foxp3 directly down-regulates miR-142-3p expression and keeps the AC9/cAMP pathway active and elevates intracellular cAMP levels (Huang et al., 2009). Thus, downregulation of miR142-3p is required for suppressor function of Treg cells.

Comparison of miRNA expression between human naïve CD4 $\mathrm{T}$ cells with Treg showed altered expression of five signature miRNAs (miR-21, -31, -125a, -181c, and -374) in Treg (Rouas et al., 2009). miR-31 and miR-125a were strongly down-regulated while miR-21, $-181 \mathrm{c}$, and -374 were found to be significantly up-regulated in Treg cells. miR-31 is known to target Foxp3 mRNA and negatively regulates its expression. miR-21 might be involved in positive regulation of Foxp3 expression. Functions of remaining three miRNA in Tregs are needs to be explored (Rouas et al., 2009). miRNA analysis of Tregs from normal and diabetic patients showed significant increased expression of miR-510 and decreased expression of miR-342 and miR-191 (Hezova et al., 2010). Hezova et al. hypothesized that down-regulation of miR342 in Tregs and impairement of Treg function in type 1 diabetic patients may be associated with disease progression. For better understanding the functional significance of differential expression of miR-510, miR-342, and miR-191 in Treg during type 1 diabetes need to be further investigated.

It has been shown that Foxp3 expression in thymic-derived Treg (nTreg) are more stable compared to the induced Treg (iTreg) (Zhou et al., 2008; Lal and Bromberg, 2009). It has been shown that nTreg possess demethylated $\mathrm{CpG}$ residues in their regulatory regions of the Foxp3 gene whereas it was completely methylated in the iTreg (Floess et al., 2007; Lal et al., 2009). Exposure of iTreg to DNA methyltransferase inhibitors leads to increased stability in the Foxp3 expression (Baron et al., 2007; Lal et al., 2009). Inflammatory signals modulated the epigenetic marks and affect the Foxp3 expression in Tregs (Li et al., 2010; Lal et al., 2011). Recently, it has been shown that nTreg expresses high levels of miR-10a and provides stability of Foxp3 expression whereas iTreg induced with TGF- $\beta$ alone does not express miR-10a, leading to decreased stability of Foxp3 expression. It has been reported that addition of retinoic acid (RA) together with TGF- $\beta$ induces miR10a expression in iTreg (Jeker et al., 2012). O'Shea's group showed that in TGF- $\beta$ and RA iTreg, miR-10a targets transcriptional repressor Bcl6 and co-repressor Ncor2, and inhibits the differentiation of iTreg to Tfh cells (Takahashi et al., 2012). It has been shown that miR-10a inhibits T-bet-dependent Th17 differentiation in iTreg and reduces the severity of EAE (Takahashi et al.,
2012). Recently, it has been demonstrated that miR-24 and miR210 target Foxp3 mRNA and regulates human Treg differentiation (Fayyad-Kazan et al., 2012).

These studies clearly suggest that a number of miRNAs not only regulates the development of Treg but also controls the plasticity and function of Treg. Disruption in Treg migration, differentiation, and function is known to have direct impact on controlling the inflammation and tolerance.

\section{ROLE OF miRNA IN Th17 CELLS}

Naive $\mathrm{CD}^{+} \mathrm{T}$ cells under the influence of IL- 6 and TGF$\beta$ differentiate into distinct subset called Th17 which secretes IL-17A, IL-17F, and IL-22. Th17 cells are reported to play an important role in clearance of pathogens, graft rejection, and autoimmune diseases (Segal, 2010; Wilke et al., 2011). miR-326 has been shown to be up-regulated in Th17 cells ( $\mathrm{Du}$ et al., 2009). Over-expression of miR-326 in mice-induced severe EAE which was marked by increased number of Th17 cells in CNS as well as increased expression of Th17 signature cytokines (IL17A, IL-21, IL-22, IL-23R) in Th17 cells (Du et al., 2009). E26 transformation-specific-1 (Ets-1), a known negative regulator of Th17 (Moisan et al., 2007) and acts as a functional target of miR-326 that represses the translation of Ets-1 mRNA (Du et al., 2009).

miR-155 has been reported to be linked with the development of inflammatory CD4 T cells. miR-155 $1-$ mice have been found to produce defective Th1 and Th17 cells during EAE as well as in mouse model of delayed type hypersensitivity (O'Connell et al., 2010). Naive CD4 ${ }^{+}$cells from miR-155 15 mice showed defects in in vitro differentiation of Th17 cells. GM-CSF-derived activated myeloid dendritic cells from miR-155 $1-$ mice were reported to produced IL-6, IL-23p19, IL-23p40, and TNF- $\alpha$ in significantly reduced amount. Since, IL- 6 and IL-23 secreted by dendritic cells are essential for Th17 cell development. It has been suggested that miR-155 expression in dendritic cells is required for development of inflammatory Th17 cells (O'Connell et al., 2010). miR-155 is also associated with several autoimmune diseases such as EAE (Murugaiyan et al., 2011), arthritis (Kurowska-Stolarska et al., 2011), systemic lupus erythematosus (SLE) (Leng et al., 2011), chronic gastritis, and colitis (Oertli et al., 2011). In contrast to these reports, expression of miR155 has been found to negatively regulate Th17 cells in acute coronary syndrome patients (Yao et al., 2011). Another miRNA, Let-7f was found to control the expression of IL-23R in memory $\mathrm{CD}^{+}{ }^{+} \mathrm{T}$ cells. Memory CD4 T cells showed decreased Let $7 \mathrm{f}$ and up-regulation of IL-23R in MS (Li et al., 2010). It has been established that IL-23/IL-23R signaling is essential for the maintenance of Th17. Using EAE model, Mycko et al. showed that miR-301a helps in promoting Th17 cell differentiation (Mycko et al., 2012). They also reported that silencing of miR-301a in CD4 $\mathrm{T}$ cells resulted in down-regulation of Th17-specific gene expression and did not affect the Tbx21 and Foxp3 expression. Further investigation in different subsets of $\mathrm{T}$ helper cells suggested that miR-301a-mediated STAT3 phosphorylation is essential for the Th17 cell differentiation program. Along with this effect, miR301a is known to inhibit PIAS3, a molecule known to interfere with STAT3 signaling pathway (Chung et al., 1997). Altogether, 
these studies suggested that expression of miR-301a in CD4 T cells contribute to the generation of inflammatory Th17 cells. IL-17 secreting murine Th17 and $\gamma \delta \mathrm{T}$ cells has been found to have increased expression of miR-133b and miR-206. These miRNAs were reported to present in syntenic to the $I l 17 \mathrm{a} / \mathrm{f}$ locus and their expression was co-regulated with IL-17 production (Haas et al., 2011). Further investigation in human primary CD4 T cells revealed that only $\mathrm{CD} 4^{+} \mathrm{IL}-17 \mathrm{~A}^{+} \mathrm{IFN} \gamma^{+}$Th17 cells but not $\mathrm{CD} 4{ }^{+}$IL-17A ${ }^{-}$IFN $\gamma^{+}$Th1 cells express both miR-133b and miR206. These reports suggest that various miRNAs differentially regulate the transdifferentiation of Th17 cells. In brief, there are several miRNAs that can modulate Th17 function and affect the pathogenesis of various diseases. Modulation of Th17 function and its epigenetic plasticity under inflammatory and tolerogenic conditions need further thorough investigation. How do miRNAs fine-tune the Th17 function in secondary lymphoid organs and inflamed microenvironment is not yet clear and need active investigation.

\section{FUTURE PERSPECTIVE}

During infection or inflammatory conditions set for the Th1 differentiation such as infection of Toxoplasma gondii or Mycobacterium tuberculosis, Tregs acquires Th1 phenotypes (Koch et al., 2009; Oldenhove et al., 2009). Further analysis suggested that T-bet ${ }^{+}$Treg controls the Th1 response whereas T-bet ${ }^{-}$Treg promotes Th1/Th17-mediated autoimmune diseases (Koch et al., 2009; O'Connor et al., 2010). Neutralization of IFN- $\gamma$ in graftvs.-host disease model ablates alloreactive Treg function leading to necrosis and graft rejection (Sawitzki et al., 2005). A transcription factor IRF4 was known to regulate the differentiation of CD4 T cell subsets (Lohoff et al., 2002). Conditional deletion of IRF4 in the Treg leads to the increased Th2 response and pathogenesis of the diseases (Zheng et al., 2009). Apart from the transcription factors, now several investigators are trying to understand how do miRNAs regulate the differentiation and function of the cells. Transgenic and knockout mouse models provide a valuable tool to understand the physiological significance of each of these miRNAs and understanding the function and its targets in the immune cells may revolutionize the field.

\section{REFERENCES}

Baltimore, D., Boldin, M. P., O'Connell, R. M., Rao, D. S., and Taganov, K. D. (2008). MicroRNAs: new regulators of immune cell development and function. Nat. Immunol. 9, 839-845.

Banerjee, A., Schambach, F., Dejong, C. S., Hammond, S. M., and Reiner, S. L. (2010). Micro-RNA-155 inhibits IFN-gamma signaling in CD4+ T cells. Eur. J. Immunol. 40, 225-231.

Baron, U., Floess, S., Wieczorek, G., Baumann, K., Grutzkau, A., Dong, J., et al. (2007). DNA demethylation in the human FOXP3 locus discriminates regulatory $\mathrm{T}$ cells from activated FOXP3(+) conventional

Like protein coding RNA, a numbers of ncRNAs are also induced by inflammatory signals. The timing of miRNA expression, cell-types, and mode of action may have very unique role in the cell differentiation and physiological function. The interesting part of ncRNA-mediated gene regulation is that they are processed quickly and do not have to undergo translation process to become functionally active. This makes them to response promptly to the inflammatory signals and can finetune the transcription. miRNAs are involved in the various tissue inflammations and control both immune cells (which initiate antigen-specific response and produces pro-inflammatory cytokines) and tissue stromal cells (that magnify the response by producing chemokines that recruits monocytes and granulocytes). For example, microglia cells in the brain down-regulate miR-124 leading to its activation during EAE (Ponomarev et al., 2011) whereas miR-155 and miR-326 expression increased in Th17 cells, together increase the inflammation and pathogenesis of the diseases (Du et al., 2009; O'Connell et al., 2010). There are several targets that are controlled by miRNA (Table 1) which suggests that a therapeutic approach can be employed by targeting a specific or multiple miRNAs simultaneously in an effort to achieve a strong and potent effect on a tissue-specific inflammation. Antigen-specific Tregs provide a valuable cellular therapy to induce transplantation tolerance and control the autoimmunity. However, understanding the plasticity of antigen-specific Treg and its differentiation into antigen-specific effector $\mathrm{T}$ cells in vivo due to exposure to inflammatory signals in the body imposes a caution using such cellular therapy. Future studies to understand the function of various miRNA in the Th1, Th2, Th17, and Treg and its affect on inflammatory signals may provide a novel therapeutic strategy to manipulate the antigen-specific Treg for clinical use.

\section{FUNDING}

This work was supported by Department of Biotechnology, Government of India (grant reference number BT/RLF/ Re-entry/41/2010, BT/03/IYBA/2010, and BT/PR4610/MED/30/ 720/2012). Neeraja Kulkarni and Sandip Sonar are the junior research fellow of Council of Scientific and Industrial Research, Government of India.

Berezikov, E., Chung, W. J., Willis, J., Cuppen, E., and Lai, E. C. (2007). Mammalian mirtron genes. Mol. Cell 28, 328-336.

Bluml, S., Bonelli, M., Niederreiter, B., Puchner, A., Mayr, G., Hayer, S., et al. (2011). Essential role of microRNA-155 in the pathogenesis of autoimmune arthritis in mice. Arthritis Rheum. 63, 1281-1288.

Bohnsack, M. T., Czaplinski, K., and Gorlich, D. (2004). Exportin 5 is a RanGTP-dependent dsRNAbinding protein that mediates nuclear export of pre-miRNAs. RNA 10, 185-191.

Bopp, T., Becker, C., Klein, M., KleinHessling, S., Palmetshofer, A.,
Serfling, E., et al. (2007). Cyclic adenosine monophosphate is a key component of regulatory $\mathrm{T}$ cell-mediated suppression. J. Exp. Med. 204, 1303-1310.

Bopp, T., Dehzad, N., Reuter, S., Klein, M., Ullrich, N., Stassen, M., et al. (2009). Inhibition of cAMP degradation improves regulatory $\mathrm{T}$ cell-mediated suppression. J. Immunol. 182, 4017-4024.

Brunner, C., Sindrilaru, A., Girkontaite, I., Fischer, K. D., Sunderkotter, C., and Wirth, T. (2007). BOB.1/OBF.1 controls the balance of $\mathrm{TH} 1$ and TH2 immune responses. EMBO J. 26, 3191-3202. 
Chen, C. Z., Li, L., Lodish, H. F., and Bartel, D. P. (2004). MicroRNAs modulate hematopoietic lineage differentiation. Science 303, 83-86.

Chendrimada, T. P., Gregory, R. I., Kumaraswamy, E., Norman, J., Cooch, N., Nishikura, K., et al. (2005). TRBP recruits the Dicer complex to Ago2 for microRNA processing and gene silencing. Nature 436, 740-744.

Chong, M. M., Rasmussen, J. P., Rudensky, A. Y., and Littman, D. R. (2008). The RNAseIII enzyme Drosha is critical in T cells for preventing lethal inflammatory disease. J. Exp. Med. 205, 2005-2017.

Chung, C. D., Liao, J., Liu, B., Rao, X., Jay, P., Berta, P., et al. (1997). Specific inhibition of Stat3 signal transduction by PIAS3. Science 278, 1803-1805.

Cobb, B. S., Hertweck, A., Smith, J., O'Connor, E., Graf, D., Cook, T., et al. (2006). A role for Dicer in immune regulation. J. Exp. Med. 203, 2519-2527.

Cobb, B. S., Nesterova, T. B., Thompson, E., Hertweck, A., O'Connor, E., Godwin, J., et al. (2005). T cell lineage choice and differentiation in the absence of the RNase III enzyme Dicer. J. Exp. Med. 201, 1367-1373.

Contreras, J., and Rao, D. S. (2012). MicroRNAs in inflammation and immune responses. Leukemia 26, 404-413.

Costa, F. F. (2010). Non-coding RNAs: meet thy masters. Bioessays 32, 599-608.

Curtale, G., Citarella, F., Carissimi, C., Goldoni, M., Carucci, N., Fulci, V., et al. (2010). An emerging player in the adaptive immune response: microRNA-146a is a modulator of IL-2 expression and activationinduced cell death in $\mathrm{T}$ lymphocytes. Blood 115, 265-273.

Du, C., Liu, C., Kang, J., Zhao, G., Ye, Z., Huang, S., et al. (2009). MicroRNA miR-326 regulates TH17 differentiation and is associated with the pathogenesis of multiple sclerosis. Nat. Immunol. 10, 1252-1259.

Esteller, M. (2011). Non-coding RNAs in human disease. Nat. Rev. Genet. 12, 861-874.

Fayyad-Kazan, H., Rouas, R., FayyadKazan, M., Badran, R., El Zein, N., Lewalle, P., et al. (2012). MicroRNA profile of circulating CD4-positive regulatory $\mathrm{T}$ cells in human adults and impact of differentially expressed microRNAs on expression of two genes essential to their function. J. Biol. Chem. 287, 9910-9922.
Floess, S., Freyer, J., Siewert, C., Baron, U., Olek, S., Polansky, J., et al. (2007). Epigenetic control of the foxp3 locus in regulatory $\mathrm{T}$ cells. PLoS Biol. 5:e38. doi: 10.1371/journal.pbio.0050038

Gao, Y., Lin, F., Su, J., Gao, Z., Li, Y., Yang, J., et al. (2012). Molecular mechanisms underlying the regulation and functional plasticity of FOXP3(+) regulatory T cells. Genes Immun. 13, 1-13.

Guan, H., Fan, D., Mrelashvili, D., Hao, H., Singh, N. P., Singh, U. P., et al. (2013). MicroRNA let-7e is associated with the pathogenesis of experimental autoimmune encephalomyelitis. Eur. J. Immunol. 43, 104-114.

Guerau-de-Arellano, M., Smith, K. M., Godlewski, J., Liu, Y., Winger, R., Lawler, S. E., et al. (2011). MicroRNA dysregulation in multiple sclerosis favours pro-inflammatory $\mathrm{T}$ cell-mediated autoimmunity. Brain 134, 3578-3589.

Haas, J. D., Nistala, K., Petermann, F., Saran, N., Chennupati, V., Schmitz, S., et al. (2011). Expression of miRNAs miR-133b and miR-206 in the Ill7a/f locus is co-regulated with IL-17 production in alphabeta and gammadelta T cells. PLoS ONE 6:e20171. doi: 10.1371/journal.pone.0020171

Hegazy, A. N., Peine, M., Helmstetter, C., Panse, I., Frohlich, A., Bergthaler, A., et al. (2010). Interferons direct Th2 cell reprogramming to generate a stable GATA-3(+)T-bet(+) cell subset with combined Th2 and Th1 cell functions. Immunity 32, 116-128.

Hezova, R., Slaby, O., Faltejkkova, P., Mikulkova, Z., Buresova, I., Raja, K. R., et al. (2010). microRNA-342, microRNA-191 and microRNA-510 are differentially expressed in $\mathrm{T}$ regulatory cells of type 1 diabetic patients. Cell. Immunol. 260, 70-74.

Huang, B., Zhao, J., Lei, Z., Shen, S., Li, D., Shen, G. X., et al. (2009). miR-142-3p restricts cAMP production in CD4+CD25- $\mathrm{T}$ cells and CD4+CD25+ TREG cells by targeting AC9 mRNA. EMBO Rep. 10, 180-185.

Huang, Y., Lei, Y., Zhang, H., Hou, L., Zhang, M., and Dayton, A. I. (2011). MicroRNA regulation of STAT4 protein expression: rapid and sensitive modulation of IL-12 signaling in human natural killer cells. Blood 118, 6793-6802.

Humphreys, D. T., Westman, B. J., Martin, D. I., and Preiss, T. (2005). MicroRNAs control translation initiation by inhibiting eukaryotic initiation factor $4 \mathrm{E} / \mathrm{cap}$ and poly(A) tail function. Proc. Natl. Acad. Sci. U.S.A. 102, 16961-16966.

Huntzinger, E., and Izaurralde, E. (2011). Gene silencing by microRNAs: contributions of translational repression and mRNA decay. Nat. Rev. Genet. 12, 99-110.

Hutvagner, G., McLachlan, J., Pasquinelli, A. E., Balint, E., Tuschl, T., and Zamore, P. D. (2001). A cellular function for the RNA-interference enzyme Dicer in the maturation of the let-7 small temporal RNA. Science 293, 834-838.

Hwang, H. W., Wentzel, E. A., and Mendell, J. T. (2007). A hexanucleotide element directs microRNA nuclear import. Science 315 97-100

Jakymiw, A., Lian, S., Eystathioy, T., Li, S., Satoh, M., Hamel, J. C. et al. (2005). Disruption of GW bodies impairs mammalian RNA interference. Nat. Cell Biol. 7, 1267-1274.

Jeker, L. T., Zhou, X., Gershberg, K., De Kouchkovsky, D., Morar, M. M., Stadthagen, G., et al. (2012). MicroRNA 10a marks regulatory T cells. PLoS ONE 7:e36684. doi: 10.1371/journal.pone.0036684

Jiang, S., Li, C., Olive, V., Lykken, E., Feng, F., Sevilla, J., et al. (2011). Molecular dissection of the miR-1792 cluster's critical dual roles in promoting Th1 responses and preventing inducible Treg differentiation. Blood 118, 5487-5497.

Johnston, R. J. Jr., Chang, S. Etchberger, J. F., Ortiz, C. O. and Hobert, O. (2005). MicroRNAs acting in a double-negative feedback loop to control a neuronal cell fate decision. Proc. Natl. Acad. Sci. U.S.A. 102, 12449-12454.

Jones, M. R., Quinton, L. J., Blahna, M. T., Neilson, J. R., Fu, S., Ivanov, A. R., et al. (2009). Zcchc11-dependent uridylation of microRNA directs cytokine expression. Nat. Cell Biol. $11,1157-1163$.

Kaikkonen, M. U., Lam, M. T., and Glass, C. K. (2011). Non-coding RNAs as regulators of gene expression and epigenetics. Cardiovasc. Res. 90, 430-440.

Kanno, Y., Vahedi, G., Hirahara, K., Singleton, K., and O'Shea, J. J. (2012). Transcriptional and epigenetic control of $\mathrm{T}$ helper cell specification: molecular mechanisms underlying commitment and plasticity. Annu. Rev. Immunol. 30, 707-731.

Kawahara, Y., Megraw, M., Kreider, E., Iizasa, H., Valente, L., Hatzigeorgiou, A. G., et al. (2008).
Frequency and fate of microRNA editing in human brain. Nucleic Acids Res. 36, 5270-5280.

Kawahara, Y., Zinshteyn, B. Chendrimada, T. P., Shiekhattar, R., and Nishikura, K. (2007a). RNA editing of the microRNA-151 precursor blocks cleavage by the Dicer-TRBP complex. EMBO Rep. 8, 763-769.

Kawahara, Y., Zinshteyn, B. Sethupathy, P., Iizasa, H., Hatzigeorgiou, A. G., and Nishikura, K. (2007b). Redirection of silencing targets by adenosine-toinosine editing of miRNAs. Science 315, 1137-1140.

Kim, J., Inoue, K., Ishii, J., Vanti, W. B., Voronov, S. V., Murchison, E., et al. (2007). A MicroRNA feedback circuit in midbrain dopamine neurons. Science 317, 1220-1224.

Kiriakidou, M., Tan, G. S., Lamprinaki, S., De Planell-Saguer, M., Nelson, P. T., and Mourelatos, Z. (2007). An mRNA $m 7 G$ cap bindinglike motif within human Ago2 represses translation. Cell 129, 1141-1151.

Koch, M. A., Tucker-Heard, G., Perdue, N. R., Killebrew, J. R., Urdahl, K. B., and Campbell, D. J. (2009). The transcription factor T-bet controls regulatory $\mathrm{T}$ cell homeostasis and function during type 1 inflammation. Nat. Immunol. 10, 595-602.

Kohlhaas, S., Garden, O. A., Scudamore, C., Turner, M. Okkenhaug, K., and Vigorito, E. (2009). Cutting edge: the Foxp3 target miR-155 contributes to the development of regulatory $\mathrm{T}$ cells. J. Immunol. 182, 2578-2582.

Kurowska-Stolarska, M., Alivernini, S., Ballantine, L. E., Asquith, D. L., Millar, N. L., Gilchrist, D. S., et al. (2011). MicroRNA-155 as a proinflammatory regulator in clinical and experimental arthritis. Proc. Natl. Acad. Sci. U.S.A. 108, 11193-11198.

Lal, G., and Bromberg, J. S. (2009). Epigenetic mechanisms of regulation of Foxp3 expression. Blood 114, 3727-3735.

Lal, G., Yin, N., Xu, J., Lin, M., Schroppel, S., Ding, Y., et al. (2011). Distinct inflammatory signals have physiologically divergent effects on epigenetic regulation of Foxp3 expression and Treg function. Am. J. Transplant. 11, 203-214.

Lal, G., Zhang, N., van der Touw, W., Ding, Y., Ju, W., Bottinger, E. P., et al. (2009). Epigenetic regulation of Foxp3 expression in regulatory $\mathrm{T}$ cells by DNA methylation. J. Immunol. 182, 259-273. 
Lee, E. J., Baek, M., Gusev, Y., Brackett, D. J., Nuovo, G. J., and Schmittgen, T. D. (2008). Systematic evaluation of microRNA processing patterns in tissues, cell lines, and tumors. RNA 14, 35-42.

Lee, P. P., Fitzpatrick, D. R., Beard, C., Jessup, H. K., Lehar, S., Makar, K. W., et al. (2001). A critical role for Dnmtl and DNA methylation in $\mathrm{T}$ cell development, function, and survival. Immunity 15, 763-774.

Lee, Y., Ahn, C., Han, J., Choi, H., Kim, J., Yim, J., et al. (2003). The nuclear RNase III Drosha initiates microRNA processing. Nature 425, 415-419.

Lee, Y., Hur, I., Park, S. Y., Kim, Y. K., Suh, M. R., and Kim, V. N. (2006). The role of PACT in the RNA silencing pathway. EMBO J. 25, 522-532.

Leng, R. X., Pan, H. F., Qin, W. Z., Chen, G. M., and Ye, D. Q. (2011). Role of microRNA-155 in autoimmunity. Cytokine Growth Factor Rev. 22, 141-147

Li, L., Kim, J., and Boussiotis, V. A. (2010). IL-1beta-mediated signals preferentially drive conversion of regulatory $\mathrm{T}$ cells but not conventional $\mathrm{T}$ cells into IL-17producing cells. J. Immunol. 185, 4148-4153.

Lindberg, J., and Lundeberg, J. (2010). The plasticity of the mammalian transcriptome. Genomics 95, 1-6.

Liu, J., Rivas, F. V., Wohlschlegel, J., Yates, J. R. 3rd., Parker, R., and Hannon, G. J. (2005). A role for the P-body component GW182 in microRNA function. Nat. Cell Biol. 7, 1261-1266.

Lohoff, M., Mittrucker, H. W., Prechtl, S., Bischof, S., Sommer, F., Kock, S., et al. (2002). Dysregulated T helper cell differentiation in the absence of interferon regulatory factor 4 . Proc. Natl. Acad. Sci. U.S.A. 99, 11808-11812.

Lu, K. T., Kanno, Y., Cannons, J. L., Handon, R., Bible, P., Elkahloun, A. G., et al. (2011). Functional and epigenetic studies reveal multistep differentiation and plasticity of in vitro-generated and in vivoderived follicular $\mathrm{T}$ helper cells. Immunity 35, 622-632.

Lu, L. F., Boldin, M. P., Chaudhry, A., Lin, L. L., Taganov, K. D., Hanada, T., et al. (2010). Function of miR-146a in controlling Treg cell-mediated regulation of Th1 responses. Cell 142, 914-929.

Lu, L. F., Thai, T. H., Calado, D. P., Chaudhry, A., Kubo, M., Tanaka, K., et al. (2009). Foxp3-dependent microRNA155 confers competitive fitness to regulatory $\mathrm{T}$ cells by targeting SOCS1 protein. Immunity 30, 80-91.

Lund, E., Guttinger, S., Calado, A., Dahlberg, J. E., and Kutay, U. (2004). Nuclear export of microRNA precursors. Science 303, 95-98.

Lytle, J. R., Yario, T. A., and Steitz, J. A. (2007). Target mRNAs are repressed as efficiently by microRNA-binding sites in the $5^{\prime}$ UTR as in the $3^{\prime}$ UTR. Proc. Natl. Acad. Sci. U.S.A. 104, 9667-9672.

Ma, F., Xu, S., Liu, X., Zhang, Q. Xu, X., Liu, M., et al. (2011). The microRNA miR-29 controls innate and adaptive immune responses to intracellular bacterial infection by targeting interferon-gamma. Nat. Immunol. 12, 861-869.

Marson, A., Kretschmer, K., Frampton, G. M., Jacobsen, E. S., Polansky, J. K., Macisaac, K. D., et al. (2007). Foxp3 occupancy and regulation of key target genes during T-cell stimulation. Nature 445, 931-935.

Mathonnet, G., Fabian, M. R., Svitkin, Y. V., Parsyan, A., Huck, L., Murata T., et al. (2007). MicroRNA inhibition of translation initiation in vitro by targeting the cap-binding complex eIF4F. Science 317, 1764-1767.

Mattes, J., Collison, A., Plank, M., Phipps, S., and Foster, P. S. (2009). Antag onism of microRNA-126 suppresses the effector function of $\mathrm{TH} 2$ cells and the development of allergic airways disease. Proc. Natl. Acad. Sci. U.S.A. 106, 18704-18709.

Melo, S. A., Ropero, S., Moutinho, C., Aaltonen, L. A., Yamamoto, H., Calin, G. A., et al. (2009). A TARBP2 mutation in human cancer impairs microRNA processing and DICER1 function. Nat. Genet. 41, 365-370.

Moisan, J., Grenningloh, R., Bettelli, E., Oukka, M., and Ho, I. C. (2007). Ets-1 is a negative regulator of Th17 differentiation. J. Exp. Med. 204, 2825-2835.

Monticelli, S., Ansel, K. M., Xiao, C., Socci, N. D., Krichevsky, A. M., Thai, T. H., et al. (2005). MicroRNA profiling of the murine hematopoietic system. Genome Biol. 6, R71.

Mortazavi, A., Williams, B. A., McCue, K., Schaeffer, L., and Wold, B. (2008). Mapping and quantifying mammalian transcriptomes by RNA-Seq. Nat. Methods 5, 621-628.

Muljo, S. A., Ansel, K. M. Kanellopoulou, C., Livingston, D. M., Rao, A., and Rajewsky, K. (2005). Aberrant T cell differentiation in the absence of Dicer. J. Exp. Med. 202, 261-269.

Murugaiyan, G., Beynon, V., Mittal, A., Joller, N., and Weiner, H. L. (2011).
Silencing microRNA-155 ameliorates experimental autoimmune encephalomyelitis. J. Immunol. 187, 2213-2221.

Mycko, M. P., Cichalewska, M. Machlanska, A., Cwiklinska, H., Mariasiewicz, M., and Selmaj, K. W. (2012). microRNA-301a regulation of a T-helper 17 immune response controls autoimmune demyelination. Proc. Natl. Acad. Sci. U.S.A. 109, E1248-E1257.

Newman, M. A., Thomson, J. M., and Hammond, S. M. (2008). Lin-28 interaction with the Let-7 precursor loop mediates regulated microRNA processing. RNA 14, 1539-1549.

O'Connell, R. M., Kahn, D., Gibson, W. S., Round, J. L., Scholz, R. L., Chaudhuri, A. A., et al. (2010). MicroRNA-155 promotes autoimmune inflammation by enhancing inflammatory $\mathrm{T}$ cell development. Immunity 33, 607-619.

O'Connell, R. M., Rao, D. S., and Baltimore, D. (2012). microRNA regulation of inflammatory responses. Annu. Rev. Immunol. 30, 295-312.

O'Connor, R. A., Leech, M. D. Suffner, J., Hammerling, G. J., and Anderton, S. M. (2010) Myelin-reactive, TGF-beta-induced regulatory $\mathrm{T}$ cells can be programmed to develop Th1-like effector function but remain less proinflammatory than myelinreactive Th1 effectors and can suppress pathogenic $\mathrm{T}$ cell clonal expansion in vivo. J. Immunol. 185 , 7235-7243

Oertli, M., Engler, D. B., Kohler, E. Koch, M., Meyer, T. F., and Muller, A. (2011). MicroRNA-155 is essential for the $\mathrm{T}$ cell-mediated control of Helicobacter pylori infection and for the induction of chronic Gastritis and Colitis. J. Immunol. 187, 3578-3586.

Oldenhove, G., Bouladoux, N., Wohlfert, E. A., Hall, J. A., Chou, D., Dos Santos, L., et al. (2009). Decrease of Foxp3+ Treg cell number and acquisition of effector cell phenotype during lethal infection. Immunity 31, 772-786.

Orom, U. A., Nielsen, F. C., and Lund, A. H. (2008). MicroRNA-10a binds the 5'UTR of ribosomal protein mRNAs and enhances their translation. Mol. Cell 30, 460-471.

O'Shea, J. J., and Paul, W. E. (2010) Mechanisms underlying lineage commitment and plasticity of helper CD4+ T cells. Science 327, 1098-1102.

Pan, Q., Shai, O., Lee, L. J., Frey, B. J., and Blencowe, B. J. (2008). Deep surveying of alternative splicing complexity in the human transcriptome by high-throughput sequencing. Nat. Genet. 40, 1413-1415.

Pan, W., Zhu, S., Yuan, M., Cui, H., Wang, L., Luo, X., et al. (2010). MicroRNA-21 and microRNA-148a contribute to DNA hypomethylation in lupus CD4+ T cells by directly and indirectly targeting DNA methyltransferase 1 . J. Immunol. 184, 6773-6781.

Parker, R., and Song, H. (2004). The enzymes and control of eukaryotic mRNA turnover. Nat. Struct. Mol. Biol. 11, 121-127.

Petersen, C. P., Bordeleau, M. E., Pelletier, J., and Sharp, P. A. (2006). Short RNAs repress translation after initiation in mammalian cells. Mol. Cell 21, 533-542.

Pillai, R. S., Bhattacharyya, S. N., Artus, C. G., Zoller, T., Cougot, N., Basyuk, E., et al. (2005). Inhibition of translational initiation by Let-7 MicroRNA in human cells. Science 309, 1573-1576.

Ponomarev, E. D., Veremeyko, T., Barteneva, N., Krichevsky, A. M., and Weiner, H. L. (2011). MicroRNA-124 promotes microglia quiescence and suppresses EAE by deactivating macrophages via the C/EBP-alpha-PU.1 pathway. Nat. Med. 17, 64-70.

Rodriguez, A., Vigorito, E., Clare, S., Warren, M. V., Couttet, P., Soond, D. R., et al. (2007). Requirement of bic/microRNA-155 for normal immune function. Science 316, 608-611.

Rouas, R., Fayyad-Kazan, H., El Zein, N., Lewalle, P., Rothe, F., Simion, A., et al. (2009). Human natural Treg microRNA signature: role of microRNA-31 and microRNA-21 in FOXP3 expression. Eur. J. Immunol. 39, 1608-1618.

Ruby, J. G., Jan, C. H., and Bartel, D. P. (2007). Intronic microRNA precursors that bypass Drosha processing. Nature 448, 83-86.

Sawitzki, B., Kingsley, C. I., Oliveira, V., Karim, M., Herber, M., and Wood K. J. (2005). IFN-gamma production by alloantigen-reactive regulatory $\mathrm{T}$ cells is important for their regulatory function in vivo. J. Exp. Med. 201, 1925-1935.

Segal, B. M. (2010). Th17 cells in autoimmune demyelinating disease. Semin. Immunopathol. 32, 71-77.

Smith, K. M., Guerau-de-Arellano, M., Costinean, S., Williams, J. L., Bottoni, A., Mavrikis Cox, G., et al. (2012). miR-29ab1 deficiency identifies a negative feedback loop controlling Th1 bias that is dysregulated in 
multiple sclerosis. J. Immunol. 189, 1567-1576.

Sonkoly, E., Janson, P., Majuri, M. L., Savinko, T., Fyhrquist, N., Eidsmo, L., et al. (2010). MiR-155 is overexpressed in patients with atopic dermatitis and modulates T-cell proliferative responses by targeting cytotoxic $\mathrm{T}$ lymphocyteassociated antigen 4. J. Allergy Clin. Immunol. 126, 581-589.e1-20.

Stahl, H. F., Fauti, T., Ullrich, N., Bopp, T., Kubach, J., Rust, W., et al. (2009). miR-155 inhibition sensitizes CD4+ Th cells for TREG mediated suppression. PLoS ONE 4:e7158. doi: 10.1371/journal.pone.0007158

Steiner, D. F., Thomas, M. F., Hu, J. K., Yang, Z., Babiarz, J. E., Allen, C. D., et al. (2011). MicroRNA-29 regulates T-box transcription factors and interferon-gamma production in helper T cells. Immunity 35, 169-181.

Taft, R. J., Glazov, E. A., Cloonan, N., Simons, C., Stephen, S., Faulkner, G. J., et al. (2009). Tiny RNAs associated with transcription start sites in animals. Nat. Genet. 41, 572-578.

Takahashi, H., Kanno, T., Nakayamada, S., Hirahara, K., Sciume, G., Muljo, S. A., et al. (2012). TGF-beta and retinoic acid induce the microRNA miR-10a, which targets Bcl-6 and constrains the plasticity of helper T cells. Nat. Immunol. 13, 587-595.

Tomankova, T., Petrek, M., Gallo, J., and Kriegova, E. (2011). MicroRNAs: emerging regulators of immune-mediated diseases. Scand. J. Immunol. 75, 129-141.

Triboulet, R., Chang, H. M., Lapierre, R. J., and Gregory, R. I. (2009). Post-transcriptional control of DGCR8 expression by the Microprocessor. RNA 15, 1005-1011.

Tsuji, M., Komatsu, N., Kawamoto, S., Suzuki, K., Kanagawa, O., Honjo, T., et al. (2009). Preferential generation of follicular B helper $\mathrm{T}$ cells from Foxp3+ $\mathrm{T}$ cells in gut Peyer's patches. Science 323, 1488-1492.

Turner, M. J., and Slack, F. J. (2009). Transcriptional control of microRNA expression in C. elegans: promoting better understanding. RNA Biol. 6, 49-53.

Valadi, H., Ekstrom, K., Bossios, A., Sjostrand, M., Lee, J. J., and Lotvall, J. O. (2007). Exosome-mediated transfer of mRNAs and microRNAs is a novel mechanism of genetic exchange between cells. Nat. Cell Biol. 9, 654-659.

Vasudevan, S., and Steitz, J. A. (2007). AU-rich-element-mediated upregulation of translation by FXR1 and Argonaute 2. Cell 128, 1105-1118.

Vasudevan, S., Tong, Y., and Steitz, J. A. (2007). Switching from repression to activation: microRNAs can up-regulate translation. Science 318, 1931-1934.

Wang, Y., Souabni, A., Flavell, R. A., and Wan, Y. Y. (2010). An intrinsic mechanism predisposes Foxp3expressing regulatory $\mathrm{T}$ cells to Th2 conversion in vivo. J. Immunol. 185, 5983-5992.

Wilhelm, B. T., Marguerat, S., Watt, S., Schubert, F., Wood, V., Goodhead, I., et al. (2008). Dynamic repertoire of a eukaryotic transcriptome surveyed at singlenucleotide resolution. Nature 453, 1239-1243.

Wilke, C. M., Bishop, K., Fox, D., and Zou, W. (2011). Deciphering the role of Th17 cells in human disease. Trends Immunol. 32, 603-611.
Wu, L., Fan, J., and Belasco, J. G. (2006). MicroRNAs direct rapid deadenylation of mRNA. Proc. Natl. Acad. Sci. U.S.A. 103, 4034-4039.

Wu, Z., Lu, H., Sheng, J., and Li, L. (2012). Inductive microRNA21 impairs anti-mycobacterial responses by targeting IL- 12 and Bcl-2. FEBS Lett. 586, 2459-2467.

Xu, L., Kitani, A., Fuss, I., and Strober, W. (2007). Cutting edge: regulatory T cells induce CD4+CD25-Foxp3- T cells or are self-induced to become Th17 cells in the absence of exogenous TGF-beta. J. Immunol. 178, 6725-6729.

Yao, R., Ma, Y., Du, Y., Liao, M., Li, H., Liang, W., et al. (2011). The altered expression of inflammation-related microRNAs with microRNA-155 expression correlates with Th17 differentiation in patients with acute coronary syndrome. Cell. Mol. Immunol. 8, 486-495.

Yu, D., Rao, S., Tsai, L. M., Lee, S. K., He, Y., Sutcliffe, E. L., et al. (2009). The transcriptional repressor Bcl-6 directs $\mathrm{T}$ follicular helper cell lineage commitment. Immunity 31, 457-468.

Zaretsky, A. G., Taylor, J. J., King, I. L., Marshall, F. A., Mohrs, M., and Pearce, E. J. (2009). T follicular helper cells differentiate from Th2 cells in response to helminth antigens. J. Exp. Med. 206, 991-999.

Zhao, S., Wang, Y., Liang, Y., Zhao, M., Long, H., Ding, S., et al. (2011). MicroRNA-126 regulates DNA methylation in CD4+ T cells and contributes to systemic lupus erythematosus by targeting DNA methyltransferase 1. Arthritis Rheum. 63, 1376-1386.

Zheng, Y., Chaudhry, A., Kas, A., Deroos, P., Kim, J. M., Chu, T.
T., et al. (2009). Regulatory T-cell suppressor program co-opts transcription factor IRF4 to control $\mathrm{T}(\mathrm{H}) 2$ responses. Nature 458, 351-356.

Zheng, Y., Josefowicz, S. Z., Kas, A., Chu, T. T., Gavin, M. A., and Rudensky, A. Y. (2007). Genomewide analysis of Foxp3 target genes in developing and mature regulatory $\mathrm{T}$ cells. Nature 445, 936-940.

Zhou, X., Jeker, L. T., Fife, B. T., Zhu, S., Anderson, M. S., McManus, M. T., et al. (2008). Selective miRNA disruption in $\mathrm{T}$ reg cells leads to uncontrolled autoimmunity. J. Exp. Med. 205, 1983-1991.

Conflict of Interest Statement: The authors declare that the research was conducted in the absence of any commercial or financial relationships that could be construed as a potential conflict of interest.

Received: 31 August 2012; accepted: 10 January 2013; published online: 31 January 2013.

Citation: Sethi A, Kulkarni N, Sonar S and Lal G (2013) Role of miRNAs in CD4 $T$ cell plasticity during inflammation and tolerance. Front. Gene. 4:8. doi: 10.3389/fgene. 2013.00008

This article was submitted to Frontiers in Non-Coding RNA, a specialty of Frontiers in Genetics.

Copyright () 2013 Sethi, Kulkarni, Sonar and Lal. This is an open-access article distributed under the terms of the Creative Commons Attribution License, which permits use, distribution and reproduction in other forums, provided the original authors and source are credited and subject to any copyright notices concerning any third-party graphics etc. 